Eastern Illinois University

The Keep

Faculty Research and Creative Activity

Communication Disorders \& Sciences

January 1994

\title{
Relation between phonologic difficulty and the occurrence of disfluencies in the early stage of stuttering
}

\author{
Rebecca Throneburg \\ Eastern Illinois University, rmthroneburg@eiu.edu \\ Ehud Yairi \\ University of Illinois at Urbana-Champaign \\ Elaine P. Paden \\ University of Illinois at Urbana-Champaign
}

Follow this and additional works at: http://thekeep.eiu.edu/commdis_fac

Part of the Communication Sciences and Disorders Commons

\section{Recommended Citation}

Throneburg, Rebecca; Yairi, Ehud; and Paden, Elaine P., "Relation between phonologic difficulty and the occurrence of disfluencies in the early stage of stuttering" (1994). Faculty Research and Creative Activity. 6.

http://thekeep.eiu.edu/commdis_fac/6 


\title{
RELATION BETWEEN PHONOLOGIC DIFFICULTY AND THE OCCURRENCE OF DISFLUENCIES IN THE EARLY STAGE OF STUTTERING
}

\author{
By Rebecca Nierrnann Throneburg, Ehud Yairi and Elaine P. Paden
}

People who stutter, especially children, have often been reported to exhibit a wide range of concomitant communication problems including articulation and phonologic deficiencies. This study investigated the relation between the phonologic difficulty of words and the point at which stuttering-like disfluencies occurred in the speech of preschool children identified as having a stuttering problem $(n=24)$. The children were divided into subgroups according to stuttering severity and phonologic ability. A spontaneous speech sample of approximately 1,000 words was tape-recorded from each child, and perceived disfluencies were identified. The phonologic difficulty of each word on which there was a stuttering-like disfluency and of each fluent word immediately following such a disfluency was categorized. The proportion of words in each child's speech sample that contained each category of phonologic difficulty was determined. The data showed that the proportion of disfluent and immediately following words in each type of phonologic difficulty closely resembled the proportion of words in the speech sample of the same type of difficulty. There were no significant differences between the subgroups of stutterers. We concluded, therefore, that the phonologic difficulty of the disfluent word, and the fluent word following it, did not contribute to fluency breakdown regardless of the childrens' stuttering severity or phonologic ability.

KEY WORDS: stuttering, disfluency, phonologic, preschool

The influence of linguistic factors on the occurrence of stuttering has been known since the early publications of Brown (1938) and Johnson and Brown (1935). Brown found that words beginning with consonants are more likely to be stuttered than words beginning with vowels. Johnson and Brown (1935) and Hahn (1942) theorized that a general ranking of difficulty of sounds is possible for adults who stutter (as a group). They discovered, however, that individuals vary widely on sounds associated with stuttering. At the conclusion of his comprehensive work on the loci of stuttering, Brown (1945) reported that the occurrence of stuttering in the speech of adults who stutter seems to be related to phonetic factors, grammatical factors, word position in a sentence, and word length.

Research on linguistic factors associated with the occurrence of stuttering in the speech of young children has been rather limited. Bloodstein (1974) and Bloodstain and Grossman (1981) analyzed the speech of young children who stuttered and reported that the occurrence of stuttering is not influenced by the initial phonerne. Rather, function words (e.g., prepositions, articles) at the beginning of syntactic units and monosyllabic words were most likely to be stuttered (Bloodstein \& Grossman, 1981; Wall, Starkweather, \& Cairns, 1981). Similar conclusions concerning the relation of initial 
consonants/vowels and monosyllabic words to the occurrence of disfluencies in the speech of normally fluent preschool children were reached by Silverman (1975).

It is interesting that despite the numerous reports that children who stutter often have concomitant articulation disorders (see review by Nippold, 1990) or phonologic disorders (Louko, Edwards, \& Conture, 1991) and the suggestion that articulatory skill is one basis for subgrouping (St. Louis \& Hinzman, 1988; St. Louis, 1991; Van Riper, 1982), little attention has been given to the effect of phonologic difficulty on the occurrence of stuttering in children. It is possible that the speech difficulties of both children who stutter and children with disordered phonology may result from problems with the central premotor planning of the speech act (Postma, Kolk, \& Povel, 1990; Ingram, 1976). At the central premotor planning stage, phonemes are selected and placed in proper order (Kent, 1976). Late-developing phonologic skills, such as complex syllable shapes, multisyllabic words, and late-developing phoneroes may require high-level pre-motor planning.

An interaction between stuttering and phonologic difficulty may also present itself at a lower level. Investigators have proposed that the main deficit in stuttering is one of neuromotor discoordination affecting the speech musculature and perhaps other motor functions (MacKay \& MacDonald, 1984; Perkins, 1976; St. Louis, 1991; Van Riper, 1982). Thus, the demands that difficult or complex phonologic structures place upon an inferior motor system may result in more stuttering. Interestingly, deficits in motor skills have also been used to explain phonologic disorders (Jenkins \& Lohr, 1964).

The objective of this study was to determine whether the occurrence of disfluencies most typical of stuttering in preschool-age children is influenced by the phonologic difficulty of the disfluent word. Late-developing sounds, multisyllables, and complex syllable shapes were considered to make words phonologically difficult. Because it is known that pre-school-age children have difficulty distinguishing word boundaries (Kamhi, Lee, \& Nelson, 1985) and stuttering is often called an anticipatory response (Bloodstein, 1972), the phonologic difficulty of the first word immediately following the disfluent word was also investigated. Such information may lead to a better understanding of the hierarchy involved in the production of early forms of stuttered speech before other developments set in. Subgroups according to phono-logic ability and stuttering severity will be used to focus on each of the two parameters.

\section{Method}

\section{Subjects}

The subjects were 24 preschool children who stutter, selected from a group of 75 children who stutter that participated in the stuttering research project at the University of Illinois. The ages of the 24 subjects were between 29 and 59 months, with a mean age of 40.5 months ( $\mathrm{SD}=9.1$ months). Nine of the subjects were girls, and 15 were boys. To be included in the study each child had to meet the following criteria: 
1. Parental diagnosis. One parent, or both parents when available, regarded the child as having a "stuttering problem."

2. Speech-language pathologist diagnosis, Two certified speech-language pathologists independently diagnosed the child as exhibiting a "stuttering problem."

3. Severity rating. The stuttering severity was rated at least 2 on a 8 -point scale $(0=$ normal speech, $1=$ very mild stuttering, $4=$ moderate stuttering, and $7=$ very severe stuttering). The rating intervals were presented and explained to the parent. Ratings were made by two speech-language pathologists and one parent.

4. Number of disfluencies. The subject produced a minimum of three stuttering-like disfluencies (SLDs) per 100 syllables. These will be defined in the section on disfluency analysis.

5. Post-onset interval. The parents reported the onset of stuttering as no more than 15 months before the initial evaluation of the subject. (Twenty-two of the 24 subjects were less than 1 year post onset.)

6. Health history. The subject exhibited no history of neurological involvement.

\section{Phonologic Skill Assessment}

The Assessment of Phonological Processes-Revised (APP-R) (Hodson, 1986) was administered to all 75 children. This test assesses phonological deficiencies through the child's elicited production of 50 single-syllable and mutlisyllable words. All phonemes of American English are included, with consonants appearing in pre- and postvocalic positisions. Percentage-of-occurrence scores for 10 basic processes are derived by dividing the total number of occurrences by the possible number of occurrences for each phonological process. Their mean percentage-of-occurrence scores were the basis for classifying the children as having good or poor phonological skills.

\section{Disfluency Analysis}

A spontaneous speech sample of approximately 1,000 words was obtained from each subject during two 20-minute recordings on separate days about one week apart. The child and one parent were given Play-Doh and asked to play and talk in a natural fashion. The conversations took place in a sound-treated room and were simultaneously audioand videotaped. The speech was audio-recorded using a Crown PCC-160 microphone, a TASCAM 122 MKII cassette tape recorder, and Maxell XLII.S-90 tape. The video data were not used for the present study.

Five specially trained examiners, with several hundred hours of experience with the task, listened to the tapes and orthographically transcribed the children's utterances. The speech samples were analyzed using a system of six disfluency categories (Yairi \& Ambrose, 1992) as follows: (a) Part-Word Repetition; (b) Single-Syllable Word Repetition; (c) Dysrhythmic Phonation (primarily sound prolongation); (d) Multisyllabic Word or Phrase Repetition; (e) Interjection; (f) Revision/incomplete Phrase. The frequency of each type of disfluency per 100 syllables was calculated for each subject. For the purpose of the present investigation, however, only the first three categories, 
considered to be stuttering-like disfluencies (SLDs), were used for analysis. Although these types of disfluency are also found in the speech of normally fluent speakers, various investigators have reported that they are the most typical disfluencies in the speech of individuals who stutter (Young, 1984).

The first author rechecked the marking of disfluencies in the speech samples of $50 \%$ of the subjects. Reliability values were derived by dividing the number of agreements for location of an SLD by the number of agreements plus disagreements (Sanders, 1961). The average interjudge point-by-point reliability coefficient between the investigator and the other four examiners concerning the occurrence of any disfluency classified as a stuttering-like disfluency was 0.97 .

\section{Subject Selection and Grouping}

The 24 subjects for this study were chosen from the pool of 75 children who stutter based on their number of SLDs and mean phonological process percentage-of-occurrence .scores on the APP-R. Age was not considered in the selection of subjects.

The children were classified into two subgroups: 12 with mild stuttering and 12 with severe stuttering. The subjects in the mild group produced between 3.0 and 5.9 SLDs per 100 syllables. Those in the severe group produced more than 10 SLDs per 100 syllables. Each of the two stuttering groups comprised 6 children with good phonologic skills and 6 children with poor phonologic skills. The children were considered to have good phonologic skills if their mean phono-logic process percentage-of-occurrence score was 11 or less on the APP-R (Hodson, 1986). They were considered to have poor phonologic skills if their mean phonologic process score was 29 or more on the APP-R. The classification process resulted in four subgroups: children with (a) severe stuttering/poor phonology; (b) severe stuttering/good phonology; (c) mild stuttering/poor phonology; (d) mild stuttering/good phonology.

The ages of the children exhibiting severe stuttering/poor phonology ranged from 29 to 59 months, with a mean age of 38.2 months $(\mathrm{SD}=10.9)$. The ages of the children with severe stuttering/good phonology were between 30 and 48 months, with a mean age of 36.3 months $(\mathrm{SD}=6.8)$. The children in the mild stuttering/poor phonology subgroup were between 30 and 47 months, with a mean age of 40.7 months $(S D=7.7)$. The children exhibiting mild stuttering/good phonology ranged in age from 34 to 51 months, with a mean of 46.5 months $(\mathrm{SD}=8.5)$. Therefore, it appears that the two groups containing children with severe stuttering were slightly younger than the two groups of children with mild stuttering. There was not a clear relation between phonologic ability and the age of the subgroups.

Phonological Analysis

The phonologic difficulty of the adult target for each word on which the child evidenced a stuttering-like disfluency and for each word following such a disfluency was analyzed. Three different aspects of phonologic difficulty were included: late-developing sounds, 
complex syllable shapes (presence of clusters), and multisyllables. These three aspects, singly or combined, yielded eight categories of phonologic difficulty that were used to evaluate the disfluent and following words. The eight categories follow:

1. Not difficult. Words that were not considered to be phonologically difficult (e.g., hot, can).

2. Complex shape. Words that were phonologically simple in all respects except for canonical (syllable) shape (e.g., snow, fixed).

3. Multisyllable. Words that were phonologically simple in all respects except that they contained more than one syllable (e.g., today, somebody).

4. Late-emerging consonants. Words that were phonologically simple in all respects except that they contained late-developing sounds. The late-developing consonants according to Sander (1972) are /r, 1, integral, 3 , phi, sigma, tintegral, d[sub3]/ (e.g., chair, ball).

5. Complex shapes and multisyllables. Words that contained both of these aspects of phonologic difficulty (e.g., snowman, biggest).

6. Complex shapes and late-emerging consonants. Words that contained both of these aspects of phonologic difficulty (e.g., play, still).

7. Multisyllables and late-emerging consonants. Words that contained both of these aspects of phonologic difficulty (e.g., nothing, little).

8. Complex shapes, late-emerging sounds, and multisyllables. Words that contained all three aspects of phonologic difficulty (e.g., tractor, elephant).

\section{Data Analysis}

For each subject, each word in their speech sample containing a stuttering-like disfluency (SLD) was categorized into one of the eight phonologic difficulty types. The proportion of words with SLDs in each of the eight phonolagic difficulty categories in relation to the total number of words with SLDs in the speech sample was calculated. The same procedure was used in phonologically categorizing the first word immediately following a disfluent word. Next, the proportion of words in each subject's 1,000-word speech sample in each category of phonologic difficulty was calculated. These proportions were considered the expected values. For example, if the proportion of words with SLDs in the late-developing sounds category was similar to the proportion of words in the entire speech sample in that category, it would indicate that it was not beyond chance that those words were disfluent.

Group data were derived by computing the means and standard deviations of the proportions of disfluent words, following words, and total words in the speech sample for each category of phonologic difficulty for the various subgroups of children who stuttered.

\section{$\underline{\text { Results }}$}

In the first step of data analysis, means of the eight proportions per word category were calculated for each group: severe stuttering/poor phonology; severe stuttering/good 
phonology; mild stuttering/poor phonology; mild stuttering/good phonology. (Each subgroup contained six individuals.) Table 1 shows the mean proportions of disfluent words, next words, and all words in the speech sample across the eight categories of phonologic difficulty for each of the four subgroups.

\begin{tabular}{|c|c|c|c|c|c|c|c|c|}
\hline & NPD & CL & MS & LS & CL/MS & CL/S & $\mathbf{M S} / \mathbf{S}$ & 3 \\
\hline \multicolumn{9}{|c|}{ Severe stuttering/Good phonology } \\
\hline Disfluent word & .52 & .11 & .06 & .20 & .00 & .05 & .04 & .02 \\
\hline Next word & .50 & .09 & .07 & .21 & .00 & .06 & .05 & .02 \\
\hline Expected values & .49 & .10 & .06 & .19 & .01 & .06 & .06 & .03 \\
\hline \multicolumn{9}{|c|}{ Severe stuttering/Poor phonology } \\
\hline Disfluent word & .56 & .09 & .04 & .17 & .00 & .06 & .06 & .02 \\
\hline Next word & .44 & .07 & .09 & .19 & .01 & .07 & .09 & .04 \\
\hline Expected values & .52 & .10 & .08 & .15 & .01 & .05 & .07 & .02 \\
\hline \multicolumn{9}{|c|}{ Mild stuttering/Good phonology } \\
\hline Disfluent word & .47 & .12 & .04 & .27 & .00 & .05 & .03 & .02 \\
\hline Next word & .43 & .06 & .07 & .21 & .01 & .08 & .09 & .05 \\
\hline Expected values & .48 & .09 & .07 & .20 & .01 & .05 & .07 & .03 \\
\hline \multicolumn{9}{|c|}{ Mild stuttering/Poor phonology } \\
\hline Disfluent word & .51 & .14 & .03 & .21 & .00 & .04 & .07 & .00 \\
\hline Next word & .48 & .14 & .05 & .19 & .01 & .04 & .06 & .03 \\
\hline Expected values & .50 & .09 & .07 & .18 & .01 & .06 & .06 & .03 \\
\hline
\end{tabular}

Note. (NPD) Not Phonologically Difficult; (CL) Cluster; (MS) Multisyllabic; (LS) Late-Developing Sound; (CL/MS) Multisyllabic Word with Cluster; (CL/S) Word with Late-Developing Sound and Cluster; (MS/S) Multisyllabic Word with Late-Developing Sound; (3) Word with Multisyllables, Late-Developing Sound, and Cluster.

TABLE 1 The mean proportions of disfluent words, next words, total words In the speech sample (expected values) containing each of eight types of phonologic difficulty for each subject group $(n=6)$.

The data indicate that for each subgroup of children who stutter the largest proportion of words that were disfluent, following words, and total words in the speech sample was in the category "Not Phonologically Difficult." The proportions in this category ranged from .43 to .58 . Words that contained only the phonologic difficulty of Late-Developing Sound yielded the second highest proportions in all of the three word categories (disfluent, next, expected) for all four subgroups. The proportion of this category ranged from .15 to .27 . Other phonologic categories exhibited very small proportions.

As can be seen, the proportion of disfluent words containing each type of phonologic difficulty was rather similar to the proportion of words from the entire speech sample with the same type of phonologic difficulty (the expected value) for all the subgroups of stutterers. The differences between observed and expected values for disfluent words ranged between .00 and .07 . Only 6 of the 24 differences exceeded .03 . The proportional means for words immediately following the disfluent words (next) also resemble the mean phonologic difficulties in the entire speech sample, with only 4 of the 24 differences exceeding .03. 
Before statistical analyses, arcsin transformations were performed because of the proportional nature of the data. To test the statistical significance of the differences, a $3 \mathrm{x}$ 8 repeated measures analysis of variance (word $\mathrm{x}$ phonologic difficulty $\mathrm{x}$ group) was performed on the data. No significant effect was found for group $(\mathrm{F}=.323 ; \mathrm{df}=3,20 ; \mathrm{p}=$ .809). No significance for the word (disfluent, next, expected) was found $(\mathrm{F}=2.786 ; \mathrm{df}=$ $2,40 ; \mathrm{p}=, 074)$. The phonologic difficulty factor proved significant $(\mathrm{F}=387.624 ; \mathrm{df}=$ 7,$140 ; \mathrm{p}<.001$ ) as did the interaction between word type (disfluent, next, expected) and phonologic difficulty $(F=2.084$; of $=14,280 ; p=.013)$. To evaluate the significance of the interaction, the Tukey post hoc test was used to identify the pairs of cells with significant differences at the .05 level. The proportion of multisyllabic disfluent words was significantly less than the proportion of multisyllabic words in the speech sample or multisyllabic next words. Additionally, the proportion of disfluent words with all three types of phonologic difficulty was significantly less than the expected values and next words for that category.

Although there were significant differences between the proportions of words in the eight phonologic difficulty categories, the proportions of disfluent and following words in each phonologic difficulty category were similar to the expected values. When significant differences occurred, the proportions of phonologically difficult disfluent words were less than the expected values in the speech sample. Therefore, it would appear that phonologic difficulty does not have much of an influence on disfluency for these young children at the early stage of stuttering.

To observe the results in a more comprehensible form, the data were collapsed in two ways. First, the eight categories of phonologic difficulty were reduced into three broader categories. The category of Not Phonologically Difficult was retained. The categories of words with Clusters (CL), Multisyllables (MS), and Late-Developing Sounds (LS)'were combined to form the category of Single Element of Phonologic Difficulty (SEPD). The categories of words with Clusters and Multisyllables (CL/MS), Clusters and LateDeveloping Sounds (CL/LS), Multisyllables and Late-Developing Sounds (MS/LS), and Late-Developing Sounds, Clusters, and Multi-syllables were combined to form Multiple Elements of Phonologic Difficulty (MEPD). Second, the original four subgroups were merged according to the singular characteristics of stuttering severity or phonologic capability. The subgroups, each consisting of 12 subjects, were (a) all children with mild stuttering, (b) all children with severe stuttering, (c) all children with good phonological skills, and (d) all children with poor phonological skills.

The same proportional measurements of the observed to the expected values described earlier were also used for the combined categories and applied to merged groups of subjects. The mean proportions resulting from these calculations are presented in Table 2 . Because the groups overlapped in subjects (each subject was included in two groups) no statistical analysis was applied. 


\begin{tabular}{|c|c|c|c|}
\hline & NPD & SEPD & MEPD \\
\hline \multicolumn{4}{|c|}{ All severe stuttering } \\
\hline Disfluent word & .54 & .33 & .13 \\
\hline Next word & .47 & .36 & .17 \\
\hline Expected proportions & .51 & .34 & .15 \\
\hline \multicolumn{4}{|c|}{ All mild stuttering } \\
\hline Disfluent word & .49 & .41 & .10 \\
\hline Next word & .45 & .36 & .19 \\
\hline Expected proportions & .49 & .35 & .16 \\
\hline \multicolumn{4}{|c|}{ All poor phonology } \\
\hline Disfluent word & .53 & .34 & .13 \\
\hline Next word & .46 & .37 & .17 \\
\hline Expected proportions & .51 & .33 & .16 \\
\hline \multicolumn{4}{|c|}{ All good phonology } \\
\hline Disfluent word & .50 & .40 & .10 \\
\hline Next word & .47 & .35 & .18 \\
\hline Expected proportions & .49 & .35 & .16 \\
\hline $\begin{array}{l}\text { Note. SEPD encomp } \\
\text { Developing Sound. M } \\
\text { Cluster, words with a } \\
\text { labic words with Late- } \\
\text { elements of phonologi }\end{array}$ & $\begin{array}{l}\text { lust } \\
\text { omp } \\
\text { glopir } \\
\text { g Sc }\end{array}$ & $\begin{array}{l}\text { isyllab } \\
\text { Itisylla } \\
\text { and C } \\
\text { d worc }\end{array}$ & $\begin{array}{l}\text { Late- } \\
\text { ds with } \\
\text { Aultisyl- } \\
\text { all three }\end{array}$ \\
\hline
\end{tabular}

TABLE 2 The mean proportions of stuttered words, next words, and total words in the speech sample (expected proportions) containing No Phonologlc Difficulty (HPD), a Single Element of Phonologic Difficulty (SEPD), and Multiple Elements of Phonologic Difficulty (MEPD) for each subject group $(n=12)$.

Visual inspection of these collapsed data also indicates that the majority of disfluent words, next words, and words in the entire speech sample were classified as Not Phonologically Difficult. The proportions of all classes of words decrease as the phonologic difficulty increases. The proportions of disfluent and next words in each phonologic difficulty category were near the expected values for all the subgroups. The collapsing of categories and the merging of subject groups did not influence the data appreciably. Once again it appears that phonologic difficulty has little influence on stuttering for any of these subgroups of stutterers.

In summary, regrouping subjects and examining three or eight categories of phonologic difficulty did not influence the trends found throughout the data. There were no large differences between the subgroups of children who stutter, and phonologic difficulty did not appear to influence the occurrence of stuttering-like disfluencies.

\section{$\underline{\text { Discussion }}$}


The present data, derived from the verbal output of 24 young children who stutter with a total language corpus of over 24,000 words, indicated that phonologic difficulty, as defined by our study (see Phonologic Analysis above), was not a factor that had a clear influence on the occurrence of stuttering-like disfluencies. Most of the words that contained stuttering-like disfluencies were not phonologically difficult or had only a single element of phonologic difficulty. Word-bound factors such as the presence of latedeveloping sounds, complex syllable shape, and/or multisyllables did not influence the occurrence of disfluencies above chance level. With few exceptions, the proportion of disfluent words that contained each type of phonologic difficulty was very similar to the proportion of words in the speech sample with that type of difficulty. In fact, when significant differences occurred, the proportion of phonologically difficult disfluent words was less than the expected values in the speech sample.

It was found that the proportional occurrence of each type of phonologic difficulty of the next words also closely resembled the proportional occurrence of that type of phonologic difficulty in the speech sample. Therefore, it also appears that the phonologic difficulty of the upcoming word is not a factor that influences the occurrence of stuttering-like disfluencies. The overall negative finding is amplified in that each of the four subgroups, representing the extremes in phonologic capabilities and stuttering severity in the larger pool of 75 children, evidenced distributions of disfluent words and following words with phonologic difficulties that approximated the distribution of phonologic difficulty throughout the speech samples.

Generally speaking, the present results do not seem to support various hypotheses on the relation between stuttering and phonology. To begin with, it is interesting to note that when selecting 24 subjects from a data pool of 75 young children who stutter, no children were found with profound phonologic deficits, and only 5 subjects, or $7 \%$ of the original pool, had severe phonologic disorders as evidenced by their scores on the Assessment of Phonological Processes-Revised (Hodson,1986). Fifty normally speaking control subjects who participated in a longitudinal study of stuttering (but were not included in the present investigation) were also given the APP-R. It is interesting to note that of these control subjects, none evidenced profound phonologic deficits and $3(6 \%)$ had severe phonologic disorders. If there is a strong relation between stuttering and disordered phonology it would be expected that a larger proportion of the stutterers than nonstutterers would have severe and profound phonological disorders.

Second, past research has found that stuttering in adult individuals is often influenced by linguistic factors such as initial phoneme, word length, and grammatical function (Brown, 1945). The present findings, however, indicate that phonologic difficulty is not one of the factors that exerts a powerful influence on the occurrence of early stuttering in preschool children. The findings agree with Bloodstein and Grossman's (1981) research in that the children's disfluencies occurred more on single-syllable than multisyllabic words; however, the proportion of single-syllable words in the speech sample of the children greatly exceeded that of the multisyllabic words. It appeared that word-bound factors, including difficult sounds within the word and complex syllable shapes, did not influence 
the occurrence of disfluencies. Perhaps phonologic influences may be more characteristic of advanced than early stuttering.

From a theoretical point of view, to the extent that phono-logic difficulty reflects the complexity of the articulatory gestures, the findings do not seem to support the motor disco-ordination hypothesis of stuttering. Perhaps phonologic difficulty, as defined by the present study, is not a sensitive indicator of the motor demand placed on the speech system. Likewise, the assertion that speech difficulties of children who stutter may result from problems with the central pre-motor planning of the speech act (Postma, Kolk, \& Povel, 1990; Ingram, 1976) is not supported by the present findings. If young children who stutter (with or without accompanying phonologic disorders) have a general speechplanning problem, as suggested by these authors, the results of the present study imply that this problem is not aggravated by words that are phonologically more difficult.

Although the present data do not show a systematic, predictable relation between phonologic difficulty and the occurrence of stuttering-like disfluencies at the early stage of stuttering, such relation may be formed as the problem progresses and becomes chronic. Future studies should concentrate on the developmental aspect of this phenomenon, with special reference to the post-onset interval. Also, attention might be given to the few subjects who exhibited somewhat closer interaction between phonologic difficulties and disfluencies. Although they were not analyzed further within the procedures of this study, they could constitute a subgroup in other aspects as well.

Acknowledgment

The system for categorizing phonological difficulty was originally devised by Susan A. Moss and Elaine P. Paden and used in an unpublished doctoral dissertation (University of Illinois, 1986). This research was supported by grant \#R01 -DC00459 from the National Institute of Deafness and Other Communicative Disorders; principal investigator, Ehud Yairi.

\section{References}

Bloodstein, O. (1972). The anticipatory struggle hypothesis: Implications of research in variability of stuttering. Journal of Speech and Hearing Research, 15, 487-494,

Bloodstein, O. (1974). The rules of early stuttering. Journal of Speech and Hearing Disorders, 39, 379-394.

Bloodstein, O., \& Grossman, M. (1981). Early stutterings: Some aspects of their form and distribution. Journal of Speech and Hearing Research, 24, 298-302.

Brown, S. (1938). A further study of stuttering in relation to various speech sounds. The Quarterly Journal of Speech, 24, 390-397. 
Brown, S. (1945). The loci of stutterings in the speech sequence. Journal of Speech Disorders, 10, 181-192.

Hahn, E. (1942). A study of the relationship between stuttering and phonetic factors in oral reading. Journal of Speech Disorders, 39, 143-151.

Hodson, B. (1986). The assessment of phonological processes -- revised. Austin, TX: Pro-Ed.

Ingram, D. (1976). Phonological disability in children. New York: Elsevier.

Jenkins, E., \& Lohr, F. (1964). Severe articulation disorders and motor ability. Journal of Speech and Hearing Disorders, 29, 286-292.

Johnson, W., \& Brown, S. (1935). Stuttering in relation to various speech sounds. The Quarterly Journal of Speech, 21,481-496.

Kahmi, A., Lee, R., \& Nelson, L. (1985). Word, syllable, and sound awareness in language disordered children. Journal of Speech and Hearing Disorders, 50, 207-212.

Kent, R. (1976). Models of speech production. In Norman Izzass (Ed.), Contemporary issues in experimental phonetics (pp. 79101). New York: Academic Press.

Louko, L., Edwards, M., \& Conturs, E. (1991). Phonological characteristics of young stutterers and their normally fluent peers: Preliminary observations. Journal of Fluency Disorders, 15, 191-210.

MacKay, D., \& McDonald, M. (1984). Stuttering as a sequencing and timing disorder. In R. Curlee \& W. Perkins (Eds.), Nature and treatment of stuttering: New directions (pp. 261-282). San Diego, CA: College-Hill.

Nippold, M. (1990). Concomitant speech and language disorders in stuttering children: A critique of the literature. Journal of Speech and Hearing Disorders, 55, 5140.

Perkins, W., Rudae, J., Johnson, L., \& Bell, J. (1976). Discoordination of phonation and respiration. Journal of Speech and Hearing Research, 19, 666-680.

Postma, A., Kolk, H., \& Povel, D. (1990). Speech planning and execution in stutterers. Journal of Fluency Disorders, 15, 49-59.

Sander, E. (1961). Reliability of the Iowa speech disfluency test. Journal of Speech and Hearing Disorders, 7, 21-30.

Sander, E. (1972). When are speech sounds learned. Journal of Speech and Hearing Disorders, 37, 55-63. 
Silverman, E. (1975). Effect of selected word attributes on pre-schoolers' speech disfluency: Initial phoneme and length. Journal of Speech and Hearing Research, 18, 430-434.

St. Louis, K. (1991). The stuttering/articulation connection. In H. Peters, W. Hulstijn, \& C. Starkweather (Eds.), Speech motor control and stuttering (pp. 393-400). Amsterdam: Elsevier Science Publishers.

St. Louis, K., \& Hinzman, A. (1988). A descriptive study of speech, language, and hearing characteristics of school-age stutterers. Journal of Fluency Disorders, 18, 331355.

Van Riper, C. (1982). The nature of stuttering. Englewood Cliffs.,, NJ: Prentice Hall.

Wall, M., Starkweather, C., \& Cairns, H. (1981). Syntactic influences on stuttering in young child stutterers. Journal of FIuency Disorders, 6, 238-298.

Yairi, E., \& Ambrose, N. (1992). A longitudinal study of stuttering in children: A preliminary study. Journal of Speech and Hearing Research, 35, 755-760.

Young, M. (1964). Identification of stutterers and stuttering. In D. Curies \& W. Perkins (Eds.), Nature and treatment of stuttering (pp. 13-30). San Diego, CA: College Hill. 